\title{
Assessment of the societal cost of Taenia solium in Angónia district, Mozambique
}

Chiara Trevisan ${ }^{1,2^{*}}$ (D) Brecht Devleesschauwer ${ }^{3}$, Nicolas Praet ${ }^{2}$, Alberto Pondja $^{4}$, Yunus Amade Assane $^{5,6}$, Pierre Dorny ${ }^{2,7}$, Stig Milan Thamsborg ${ }^{1}$, Pascal Magnussen ${ }^{1,8}$ and Maria Vang Johansen ${ }^{1}$

\begin{abstract}
Background: The zoonotic parasite Taenia solium is endemic in Angónia district, Tete province, Mozambique, though the burden of the disease complex is unknown.

Methods: As part of two cross-sectional studies on human and porcine cysticercosis in the area, unique epidemiological and cost data were collected in Angónia district, Mozambique in 2007. These data provided the basis for the assessment of the societal cost of T. solium in the district, which estimates the impact of the disease on human and pig populations and includes both health and economic approaches in the analysis.

Results: Approximately $0.7 \%$ (95\% Uncertainty Interval (UI), $0.4-0.9)$ and $0.4 \%$ (95\% UI, 0.2-0.6) of the total population in the district was estimated to suffer from neurocysticercosis (NCC)-associated epilepsy and headache. The estimated average number of disability-adjusted life years (DALYs) due to NCC-associated epilepsy and headache was 6 (95\% UI, 4-8) per thousand persons per year. The total annual costs due to T. solium cysticercosis were estimated at 90,000 USD (95\% UI, 39,483-201,463) of which 72\% (95\% UI, 45-91) were costs linked to human cysticercosis and $28 \%(95 \% \mathrm{UI}, 9.5-55)$ to pig production losses. The annual economic burden per NCC-associated epilepsy case in the district amounted to 33 USD (95\% UI, 10-76).

Conclusions: In this highly endemic area of Mozambique a large number of individuals suffer from symptoms associated with NCC. Healthy years of life are lost and people are left living with disabilities. Infected pork poses a serious risk to the community and affects the economy of smallholder farmers. Cost for treatment and hospitalization of patients with NCC-associated epilepsy, and lack of productivity and inability of suffering patients to work, further hinder socioeconomic development. Feasible solutions framed within a country specific algorithm and stepwise approaches are needed to control the parasite in the country.
\end{abstract}

Keywords: Taenia solium taeniosis/cysticercosis, Neurocysticercosis, Epilepsy, Migraine, Tension-type headache, Disability-adjusted life years: Societal cost, Zoonoses

\section{Background}

Taenia solium taeniosis/cysticercosis (TSTC) is a zoonotic disease complex currently challenging the public health and agricultural sectors in many low-income countries. Taenia solium is endemic in countries of Africa, Asia and Latin America, hindering growth and socioeconomic development [1-3].

\footnotetext{
*Correspondence: ctrevisan@itg.be; trevisanchia@gmail.com

'Department of Veterinary and Animal Sciences, Faculty of Health and Medical Sciences, University of Copenhagen, Frederiksberg, Denmark

${ }^{2}$ Department of Biomedical Sciences, Institute of Tropical Medicine, Antwerp, Belgium

Full list of author information is available at the end of the article
}

Humans acquire the adult tapeworm (taeniosis) by eating raw or undercooked pork containing cysticerci. Cysticercosis is contracted by both humans and pigs after accidentally ingesting T. solium eggs in faeces from humans harbouring the adult tapeworm. In humans cysticerci may lodge in the central nervous system leading to neurocysticercosis (NCC). The disease may cause severe disorders, the most common being epilepsy and headache [4], though people can also remain asymptomatic [5].

Recent findings reported that seizures also occur in pigs with NCC and disease negatively affects their 
behaviour, posing a further burden on the welfare of affected animals $[6,7]$.

In 2013, the World Health Assembly passed the WHA66.12 resolution with the aim of eliminating TSTC as a public health problem [8]. Recent results of a study coordinated by the Foodborne Disease Burden Epidemiology Reference Group ranked T. solium as the most important foodborne parasite in the world causing a great number NCC-associated epilepsy cases and deaths, resulting in 2.8 million disability-adjusted life years (DALYs) [9]. In parallel to these studies, country-specific studies have been conducted to estimate the health and economic burden of TSTC [10-14]. These highlighted the lack of representative country-specific data and the necessity of making assumptions, possibly leading to under- or overestimations of the impact of the parasite on human and pig populations.

During the past decade studies on T. solium were conducted in Angónia district and results have shown that the parasite and all conditions for its transmission are present $[15,16]$. The parasite is likely to pose a large burden to smallholder farmers and their society in this area of the country. Angónia district is part of Tete province, located in north-western Mozambique. Smallholder farmers living in close relation to their animals mostly populate the area. Pig production plays a major role in the families' economic activity in the district [17]. In recent years the number of pigs per family has increased as farmers have seen pigs to have a quick economic turnover and are easily raised as they can be left to roam freely. However, the economic growth and development of the area has been hindered by many post-civil war socio-economic and political challenges [18]. Political instability has led to the regress of the district, making it one of the poorest of the country [19]. Lack of access to health care, education, water supply and sanitation constantly exacerbate the poor living conditions of smallholder farmers and their families.

The present study aimed at quantifying the societal cost of T. solium in Angónia district by estimating the impact of the disease on human and pig populations and including both health and economic approaches in the analysis.

\section{Methods}

\section{Study area and population}

In 2007 the total human population of the district was 330,328 people. The main occupation and most important economic activity of the district was mixed farming, including pig rearing. Pigs were mostly free-roaming during the day and dry seasons and kept confined at night and during the rainy, crop growing season $[17,20]$.

Health care access was limited in the district with only one rural hospital, four health centres and three health points and inhabitants commonly consulted traditional healers. No computed tomography (CT) scanner was available [17].

Necessary conditions for transmission of the parasite were present, namely lack of knowledge about $T$. solium, open defecation, poor sanitation, free roaming pigs, lack of slaughtering facilities with qualified meat inspectors, home slaughtering and consumption of uninspected and undercooked pork [15, 20].

Between September and November 2007 two crosssectional studies on human and porcine cysticercosis, respectively, were conducted in Angónia district, Mozambique. The lifetime prevalence of epilepsy, where screen-positive individuals were reviewed and confirmed by a neurologist, was estimated including 1723 study subjects in the study and the results on the proportion of patients with epilepsy suffering from NCC were reported according to Del Brutto et al. (2001) [21] criteria [15]. Proportions of severe progressive headache (migraine and tension-type) among patients with epilepsy were based on answers provided by structured interviews from questionnaire developed by the Cysticercosis Working Group in Eastern and Southern Africa (CWGESA) [22, 23]. Pondja et al. (2010) [20] conducted a study to estimate the prevalence of porcine cysticercosis including 661 pigs from 306 households in 11 villages across the district. The B158/B60 ELISA detecting circulating cysticercus antigens and tongue examination for submucosal cysticerci were used to diagnose porcine cysticercosis.

\section{Health burden assessment}

The health burden for the year 2007 was assessed by estimating the annual number of NCC-associated epilepsy, migraine and tension-type headache cases, and the resulting number of deaths and DALYs. Table 1 presents the parameters and related distributions used in the analysis.

Epilepsy was defined as two or more unprovoked seizures unrelated to any acute intracranial disease (e.g. cerebral malaria, meningitis), acute metabolic disorders, withdrawal of drugs or use of alcohol and occurring at least $24 \mathrm{~h}$ apart [24]. Lifetime prevalence of epilepsy was defined as the proportion of patients identified with a history of epilepsy at any time, regardless of treatment or recent seizure activity, while active epilepsy was defined as having had at least one seizure in the past year and receiving or having received treatment [25]. The prevalence of active epilepsy was $1.3 \%$ (95\% Uncertainty interval (UI), $0.8-$ 2.0 ), obtained by dividing the number of lifetime epilepsy patients receiving epilepsy treatment by the total number of study participants [23].

Patients with NCC might experience headaches that can present as migraine or tension-type 
Table 1 Parameters used to estimate the health burden due to $\mathrm{NCC}^{\mathrm{a}}$-associated epilepsy and headache (migraine and tension-type) in Angónia district

\begin{tabular}{|c|c|c|c|}
\hline Parameter & Mean $\left(95 \% \cup I^{b}\right)$ & Distributions & Reference \\
\hline $\begin{array}{l}\text { Mortality due to epilepsy } \\
\text { per } 1000\end{array}$ & $0.08(0.076-0.084)$ & $\begin{array}{l}\text { Uniform } \\
(7.6 e-05,8.4 e-05)\end{array}$ & [28] \\
\hline Prevalence of active epilepsy (\%) & $1.3(0.8-1.9)$ & $\begin{array}{l}\text { Beta } \\
(22,1701)\end{array}$ & [15] \\
\hline \multicolumn{4}{|l|}{ Proportions } \\
\hline Epilepsy associated to NCC (\%) & $51(43-59)$ & $\begin{array}{l}\text { Uniform } \\
(0.427,0.592)\end{array}$ & [15] \\
\hline Epilepsy patients receiving treatment (\%) & $15(9.4-21)$ & $\begin{array}{l}\text { Beta } \\
(22,129)\end{array}$ & [15] \\
\hline Headache among people with lifetime epilepsy (\%) & $62(54-70)$ & $\begin{array}{l}\text { Beta } \\
(94,57)\end{array}$ & [23] \\
\hline Migraine among people with headache and epilepsy (\%) & $39(30-50)$ & $\begin{array}{l}\text { Beta } \\
(37,57)\end{array}$ & [23] \\
\hline Tension-type headache among people with headache and epilepsy (\%) & $61(50-70)$ & $\begin{array}{l}\text { Beta } \\
(57,37)\end{array}$ & [23] \\
\hline \multicolumn{4}{|l|}{ Disability weights } \\
\hline Epilepsy & & & $\mathrm{GBD}^{\mathrm{C}} 2010[31]$ \\
\hline Untreated & $0.426(0.286-0.565)$ & $\begin{array}{l}\text { Uniform } \\
(0.279,0.572)\end{array}$ & \\
\hline Treated, seizure free & $0.076(0.048-0.105)$ & $\begin{array}{l}\text { Uniform } \\
(0.047,0.106)\end{array}$ & \\
\hline Headache & & & $\mathrm{GBD}^{\mathrm{C}} 2013$ [32] \\
\hline Migraine & $0.441(0.301-0.581)$ & $\begin{array}{l}\text { Uniform } \\
(0.294,0.588)\end{array}$ & \\
\hline Tension-type & $0.040(0.023-0.056)$ & $\begin{array}{l}\text { Uniform } \\
(0.022,0.057)\end{array}$ & \\
\hline
\end{tabular}

${ }^{a}$ NCC neurocysticercosis; ${ }^{\text {b }}$ Ul uncertainty interval; ${ }^{\text {C }}$ GBD 2010, 2013: Global Burden of Disease Study 2010 and 2013

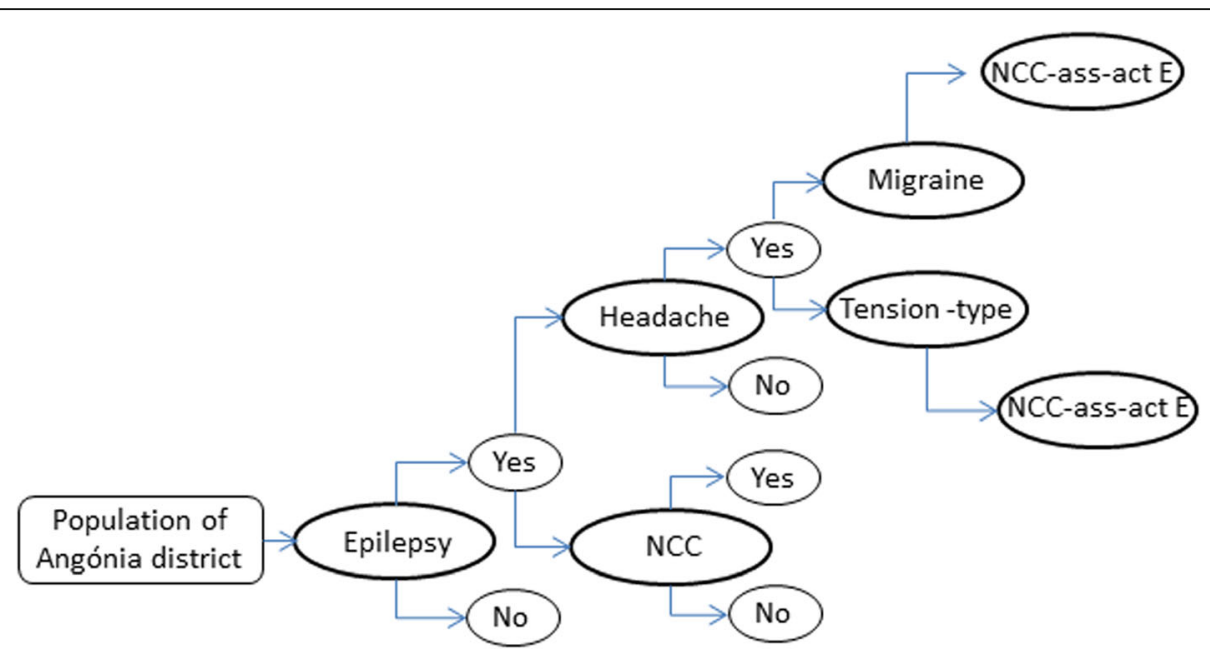

Fig. 1 Health outcome tree to estimate the proportion of patients with NCC-associated epilepsy, migraine and tension-type headache in Angónia district, Mozambique 
headache [26, 27]. Periods of recurrent headaches were reported by 94 of 151 patients with lifetime epilepsy. Of these 94 patients had migraine and the rest had tension-type headache (Table 1 ).

The burden was estimated among people with NCC-associated epilepsy, and headache was added as an extra burden on a subset of patients identified having NCC-associated epilepsy. A health outcome tree (Fig. 1) was used to obtain the proportions of the population with epilepsy, migraine and tensiontype headache due to NCC.

To estimate the mortality due to NCC-associated epilepsy, the WHO mortality rate (2008) for epilepsy in Mozambique was multiplied by the proportion of NCC-associated active epilepsy in Angónia district
$[15,28]$. Data on mortality due to headache could not be retrieved, hence it was assumed that mortality due to migraine and tension-type headache would not occur.

The number of DALYs was estimated using known methods $[29,30]$. In short: DALYs were obtained by summing years lived with disability (YLD) and years of life lost (YLL). The formulas used for the DALY calculation are described in eqs. 1 and 2.

$$
\mathrm{YLD}=\mathrm{P}^{*} \mathrm{DW}
$$

Where ' $\mathrm{P}$ ' represents the number of prevalent cases and 'DW' is the disability weight.

Table 2 Parameters used to estimate the economic burden of T. solium in Angónia district, Mozambique

\begin{tabular}{|c|c|c|c|}
\hline Parameter & Mean $\left(95 \% \cup I^{a}\right)$ & Distribution & Reference \\
\hline Study zone population & 330,328 & Fixed & [17] \\
\hline Active epilepsy (\%) & $1.3(0.8-2.0)$ & $\begin{array}{l}\text { Beta } \\
(22,1701)\end{array}$ & [15] \\
\hline NCC-associated epilepsy (\%) & $51(43-59)$ & $\begin{array}{l}\text { Uniform } \\
(0.427,0.592)\end{array}$ & [15] \\
\hline Epilepsy patients consulting a traditional healer (\%) & $23(18-28)$ & $\begin{array}{l}\text { Multinomial } \\
(0.227)\end{array}$ & [23] \\
\hline Epilepsy patients consulting a physician, a nurse or neurologist (\%) & $9.1(6-13.4)$ & $\begin{array}{l}\text { Multinomial } \\
(0.091)\end{array}$ & [23] \\
\hline Epilepsy patients without treatment (\%) & $68(62-74)$ & $\begin{array}{l}\text { Multinomial } \\
(0.682)\end{array}$ & [23] \\
\hline Visits to a traditional healer in case of epilepsy (average times per year) & $5.5(1.2-9.8)$ & $\begin{array}{l}\text { Uniform } \\
(1,10)\end{array}$ & [23] \\
\hline Visits to a doctor in case of epilepsy (average times per year) & $4.5(1.2-7.8)$ & $\begin{array}{l}\text { Uniform } \\
(1,8)\end{array}$ & [23] \\
\hline Epilepsy patients with prescribed phenobarbital (\%) & $44(33-55)$ & $\begin{array}{l}\text { Beta } \\
(36,46)\end{array}$ & [23] \\
\hline Epilepsy patients with injury referred to the hospital (\%) & $15(11-20)$ & $\begin{array}{l}\text { Beta } \\
(38,222)\end{array}$ & [23] \\
\hline Length of stay in a hospital (average days per year) & $11(1.5-20)$ & $\begin{array}{l}\text { Uniform } \\
(1,21)\end{array}$ & [23] \\
\hline Loss of working time due to epilepsy (days per year) & $16(1.7-29)$ & $\begin{array}{l}\text { Uniform } \\
(1,30)\end{array}$ & [23] \\
\hline Unemployed due to epilepsy (\%) & $2.2(0.9-5.1)$ & $\begin{array}{l}\text { Beta } \\
(6,261)\end{array}$ & [23] \\
\hline Working days per year & $266(222-310)$ & $\begin{array}{l}\text { Uniform } \\
(220,312)\end{array}$ & Assumption \\
\hline \multicolumn{4}{|l|}{$\%$ of the population } \\
\hline Economically active & 40 & Fixed & [17] \\
\hline Not economically active & 47 & Fixed & [17] \\
\hline Unemployed & 14 & Fixed & [17] \\
\hline Pig population in the study area & 20,411 & Fixed & Assumption \\
\hline Proportion of adult pigs sold per year (\%) & 33 & Fixed & Assumption \\
\hline Porcine cysticercosis prevalence based on tongue examination (\%) & $13(10-16)$ & $\begin{array}{l}\text { Beta } \\
(84,577)\end{array}$ & [20] \\
\hline
\end{tabular}

${ }^{a}$ UI Uncertainty interval 


$$
\mathrm{YLL}=\mathrm{N}^{*} \mathrm{~L}
$$

Where ' $\mathrm{N}$ ' is the number of deaths caused by disease per year and ' $\mathrm{L}$ ' is the life expectancy at the age of death in years.

Disability weights for epilepsy, migraine and tensiontype headache were based on those of the GBD study 2010 and 2013 [31, 32]. For life expectancy parameters, the GBD 2010 life expectancy table was used where life expectancy at birth is 86 years [33].

Results were computed using two variants of DALYs $[K ; r]$ (with $K$ the age weighting constant and $r$ the discount rate) and using a prevalence approach. The base case DALYs $[0 ; 0]$ were estimated without age weighting or time discounting, in line with current practice.

\section{Economic burden assessment}

The epidemiological and economic parameters used for the economic assessment are summarised in Tables 2 and 3.

Direct and indirect costs related to both human and porcine cysticercosis were included in the assessment. Direct costs related to human health included expenses for treatment such as: medical care, medicine and hospitalisation for patients with NCC-associated epilepsy. The price of a visit to a traditional healer in Angónia district varied from visit to visit hence an average price was calculated.

The indirect costs or productivity losses included the expenses related to individuals who were unable to go to work or unemployed because of NCCassociated epilepsy.

The number of working days per year was estimated at a minimum of 220 and a maximum of 312 days in order to take differences between the formal and informal sector into account.
A decision tree (Fig. 2) was used to obtain the proportions of the population with epilepsy due to NCC, with or without injury, treatment and hospitalization. The patients without injury were divided into those who sought medical care and those who did not. The patients with NCC-associated epilepsy that sought medical care were divided into: patients consulting a traditional healer and patients consulting a medical doctor, nurse or neurologist. It was assumed that all patients that got injured during an epileptic seizure would refer to the hospital and be hospitalized and the ones without injury, that sought medical care, would be treated as out-patients.

For the estimation of the losses due to porcine cysticercosis, the cysticercosis prevalence based on tongue examination, $12.7 \%$ (95\% UI, 10.3-15.5), was used. The prevalence was estimated on a sample of 661 pigs from Angónia district [20]. In Angónia district it was common practice for farmers to sell the pigs to pig traders who at purchase, would inspect the pig's tongue for cysticercosis and agree on the price. The price of a pig depended on presence or absence of infection and the animal's size. In the region, the average price reduction of a cysticercosis infected pig at slaughter was of 50\% (Gule, personal communication). This was the only agricultural factor taken into account, as porcine cysticercosis has so far not shown to have an effect on animal's productivity [4]. Losses due to carcass condemnation were not taken into account. In Angónia district meat inspection was present only at one market place, therefore the likelihood of infected meat reaching market there was very low [34]. Because reliable information on the number of slaughtering pigs was not available, the slaughtering pig population was estimated at 20,411 pigs. This number was based on the assumption that a smallholder pig farmer in Angónia district on average slaughtered one pig annually, and pigs were present in every fourth household [17]. We further assumed that only one third of the slaughtering pigs would be sold per year, as pig

Table 3 Cost parameters in USD used to estimate the economic burden of T. solium in Angónia district, Mozambique

\begin{tabular}{|c|c|c|c|}
\hline Parameter & Mean $\left(95 \% U^{\mathrm{a}}\right)$ & Distribution & Reference \\
\hline Average monthly salary & $104(30-178)$ & $\begin{array}{l}\text { Gamma } \\
(5.3,0.06)\end{array}$ & [43] \\
\hline Cost of a visit to a physician (public hospital) & $3.1(2.1-4.1)$ & $\begin{array}{l}\text { Gamma } \\
(33.4,11.1)\end{array}$ & {$[44]$} \\
\hline Cost of a traditional healer & $63(25-101)$ & $\begin{array}{l}\text { Gamma } \\
(8.5,0.15)\end{array}$ & {$[23]$} \\
\hline Cost of one day at the hospital & 2.3 & Fixed & {$[44]$} \\
\hline $\begin{array}{l}\text { Antiepileptic drugs } \\
\text { ( } 2 \text { weeks treatment) }\end{array}$ & 5 & Fixed & {$[23]$} \\
\hline Value of an adult pig & $55(30-79)$ & $\begin{array}{l}\text { Gamma } \\
(16.5,0.32)\end{array}$ & (Gule, personal communication) \\
\hline Value reduction of infected pork (\%) & 50 & Fixed & (Gule, personal communication) \\
\hline
\end{tabular}




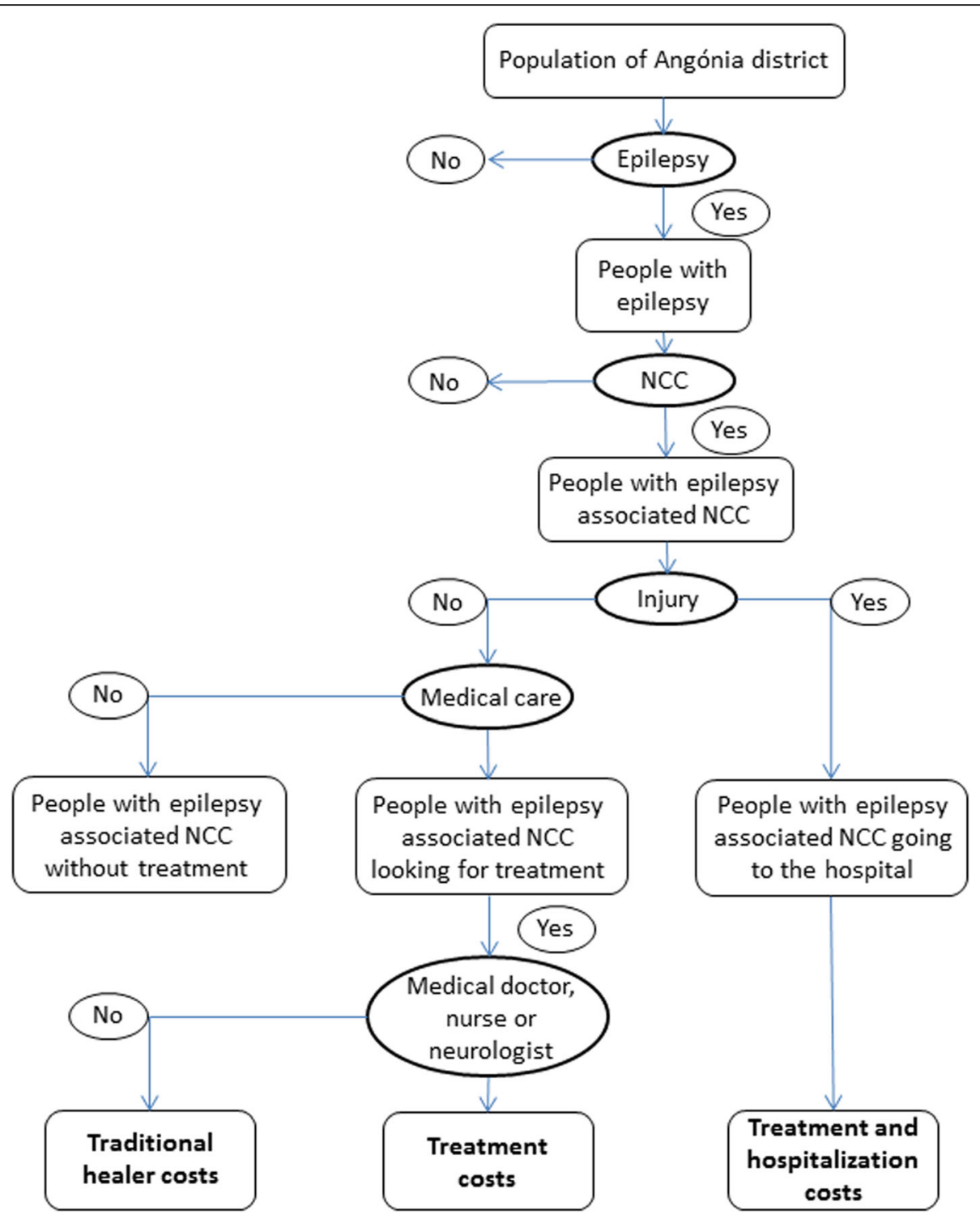

Fig. 2 Decision tree to estimate the economic burden of NCC-associated epilepsy in Angónia district, Mozambique

production for personal consumption is common in the area $[20]$.

\section{Health and economic burden assessment analyses}

All analyses were performed in R 3.2.2 [35]. Scripts are available online at https://github.com/brechtdv/tsolmozambique. The uncertainty of the parameters was modelled using Monte Carlo simulations. This allowed calculating 95\% uncertainty intervals (UI) for each result. Different distributions were used according to the type of information available for each of the variables in Tables 1, 2 and 3. The number of iterations was set to 100,000 . Sensitivity analyses were conducted to show the contribution of each uncertain variable to the overall uncertainty of the end result. The impact of the uncertainty in the different parameters on the overall uncertainty in total DALYs, costs and potential losses is shown by the partial correlation coefficients presented in the results section.

\section{Results}

Health burden assessment

Approximately $0.7 \%$ (95\% UI, 0.4-0.9) and $0.4 \%$ (95\% UI, $0.2-0.6)$ of the total population in the district was estimated to suffer from NCC-associated epilepsy and headache, respectively. Around 85\% (95\% UI, 79-91) of the diseased population never received any treatment (Table 4). Overall, it was estimated that NCC-associated 
Table 4 Estimated number of people with NCC-associated epilepsy, migraine and tension-type headache, people suffering without treatment, people dying due to NCC-associated epilepsy and pigs with cysticercosis in Angónia district, Mozambique

\begin{tabular}{lll}
\hline Estimate & Mean $\left(95 \% \mathrm{UI}^{\mathrm{a}}\right)$ & \% of total population $\left(95 \% \mathrm{UI}^{\mathrm{a}}\right)$ \\
\hline Annual number of prevalent cases of NCC-associated epilepsy & $2151(1299-3249)$ & $0.7(0.4-0.9)$ \\
People with NCC-associated epilepsy without treatment & $1837(1103-2788)$ & $0.6(0.3-0.8)$ \\
Number of deaths due to NCC-associated epilepsy & $14(11-16)$ & $0.004(0.003-0.005)$ \\
Annual number of prevalent cases of NCC-associated migraine & $527(290-855)$ & $0.2(0.1-0.3)$ \\
Annual number of prevalent cases of NCC-associated tension-type headache & $812(468-1274)$ & $0.2(0.1-0.4)$ \\
Number of pigs with cysticercosis & $2595(2098-3133)$ & $12.7(10.3-15.3)$ \\
\hline
\end{tabular}

${ }^{a}$ UI Uncertainty interval

epilepsy, migraine and tension-type headache led to more than 2003 (95\% UI, 1433-2762) healthy life years lost (Table 5), meaning 6 (95\% UI, 4-8) DALYs per 1000 persons per year. Non-fatal health outcomes were found to be the largest contributors to the overall health impact (53\% (95\% UI, 39-65). YLDs associated with NCC-headache contributed to $13 \%$ (95\% UI, 8-19) of the total DALY estimate.

When using non-uniform age weighting and a 3\% discount rate, the estimated number of DALYs[1;0.03] was 1618 (95\% UI, 1042-2411) and the estimated number of DALYs[1;0.03] per thousand person per year was 4.9 (95\% UI, 3.2-7.2). Of the total DALYs[1;0.03], 73\% (95\% UI, 61-82) were attributed to YLD and 27\% (95\% UI, 18-39) to YLL, respectively.

\section{Economic burden assessment}

Taenia solium led to an economic loss of around 90,000 USD (95\% UI, 39,483-201,463) of which 72\% (95\% UI, 45-91) were costs linked to human cysticercosis and $28 \%$ (95\% UI, 9.5-55) were due to pig production losses (Table 6). The annual economic burden per case of NCC-associated epilepsy in the district amounted at 33 USD (95\% UI, 10-76). The economic burden of NCC- associated epilepsy was dominated in particular by the production losses. Direct costs due to hospitalization were the next major contributor to the losses, although contributed only to $12 \%$ (95\% UI, 5-24) of the total costs for NCC-associated epilepsy.

Agricultural losses due to reduced value of slaughtered pigs accounted for almost one third of the total costs (28\% (95\% UI, 9.5-55)).

\section{Sensitivity analyses}

Figures 3 and 4 show the partial correlations coefficients, displaying the impact of the different parameters on the uncertainty of the overall estimates.

\section{Discussion}

The study has shown that in this T. solium endemic area of Mozambique the parasite affects the livelihood of subsistence farmers and their society by reducing their societal and economic wellbeing. Based on data, collected in parallel from human and pigs in Angónia district, the present assessment revealed that NCCassociated epilepsy and headache led to 6 (95\% UI, 4-8) DALYs per thousand persons per year, costing this society more than 90,000 (95\% UI, 39,483-201,463) USD.

Table 5 Estimated prevalent Years Lived with Disability (YLDs), Years of Life Lost (YLLs) and Disability-Adjusted Life Years (DALYs) for NCC-associated epilepsy, migraine and tension-type headache in Angónia district, Mozambique

\begin{tabular}{|c|c|c|}
\hline Estimate & Mean $\left(95 \% \mathrm{UI}^{\mathrm{a}}\right)$ & $\begin{array}{l}\text { \% contribution } \\
\text { to total DALY }\left(95 \% \mathrm{UI}^{\mathrm{a}}\right)\end{array}$ \\
\hline $\begin{array}{l}\text { YLD NCC-associated } \\
\text { epilepsy }\end{array}$ & $806(415-1368)$ & $39(28-51)$ \\
\hline $\begin{array}{l}\text { YLD NCC-associated } \\
\text { migraine }\end{array}$ & $233(111-415)$ & $11(7-18)$ \\
\hline $\begin{array}{l}\text { YLD NCC-associated } \\
\text { tension-type headache }\end{array}$ & $32(14-59)$ & $1.6(0.8-2.6)$ \\
\hline $\begin{array}{l}\text { YLL NCC-associated } \\
\text { epilepsy }\end{array}$ & $932(781-1088)$ & $47(35-61)$ \\
\hline Total DALYS* & $\begin{array}{l}2003 \\
(1433-2762)\end{array}$ & 100 \\
\hline DALYs per 1000 persons & $6(4-8)$ & 100 \\
\hline
\end{tabular}

\footnotetext{
${ }^{a}$ UI Uncertainty interval
} 
Table 6 Estimated direct and indirect annual costs due to $T$. solium in humans and pigs in Angónia district, Mozambique

\begin{tabular}{lll}
\hline Type of cost & Mean USD & $\left(95 \% \mathrm{UI}^{\mathrm{a}}\right)$ \\
\hline Hospital & 7945 & $(4312-13,019)$ \\
Antiepileptic treatment & 1501 & $(1038-2100)$ \\
Medical doctor (public hospital) & 14 & $(3-27)$ \\
Traditional healer & 312 & $(56-758)$ \\
Inactivity & 61,462 & $(11,131-166,964)$ \\
Pig losses & 22,282 & $(12,315-35,647)$ \\
Total costs & 93,370 & $(39,483-201,463)$ \\
Price per NCC-associated epilepsy case & 33 & $(10-76)$ \\
\hline ar Unceanty
\end{tabular}

${ }^{a}$ UI Uncertainty interva

Compared to other studies assessing the burden of $T$. solium, the estimated DALYs of this study were higher whereas the cost estimates for the district were lower.

This study is the third to use DALYs to estimate the health burden of T. solium in Africa and the second to include headache data in the assessment. In Africa, the first, carried out in Cameroon, estimated a number of 9.0 DALYs per 1000 person-years [13], while the second, carried out in Tanzania, estimated a number of 0.7 DALYs per 1000 person-years [14]. Health burden assessments have also been performed in Mexico, Nepal and India, where the author estimated $0.25(0.12-0.46), 0.5(0.2-1.1)$ and $1.7(0.8-3.4)$ DALYs per thousand persons per year, respectively $[10,12,36]$. The reason for the high health burden in Angónia district is likely to be an added effect of a) being a rural area with low socio-economic status, b) the presence of all risk factors for T. solium and c) no awareness of the disease in the health or agricultural sectors. In Angónia district, the prevalence of epilepsy was twice as high and the proportion of NCC in subjects with epilepsy was three times as high compared to Tanzania. To estimate the years of life lost we used the GBD 2010 life expectancy, these increased the results1.25 fold compared to using the standard life expectancy table of CoaleDemeny [37] and finally the inclusion of headache further increased the result 1.1 fold.

In Angónia district around 85\% (95\% UI, 79-91) of the patients with NCC-associated epilepsy never received treatment while in Tanzania over half of the diseased population was left untreated. As the disability weights for untreated epilepsy cases are higher than the ones for treated epilepsy, a higher number of DALYs per 1000 persons per year was expected in the district.

Headache data were included for the first time in an assessment of the burden of T. solium in Africa. Based on the data, the model estimated that in Angónia district $0.4 \%$ (95\% UI, 0.2-0.6) of the total population suffered from NCC-associated headache. Bhattarai et al. (2012) assessed the burden of NCC-associated headache in Mexico and estimated that $0.08 \%$ of the population was suffering. The results in the current study are five times higher. In this study, headache was added as an additional burden on a subset of patients with NCCassociated epilepsy, partly explaining a higher burden in Angónia district. To estimate the burden of NCCassociated headache in Mexico, Bhattarai et al. (2012) used the proportion of NCC-associated headache found in a systematic review by Carabin et al. (2011). As the review did not mention what type of headache was taken into consideration, we preferred not to use such extrapolation but use a different approach. In this study migraine and tension-type headache were added as an additional burden for a subset of patients with NCCassociated epilepsy, however NCC associated headache in non-epileptics was not calculated.

In our assessments the contribution of YLD and YLL to the total DALY was $53 \%$ and $47 \%$, respectively. These figures indicate that in this study the disease had almost an equal impact on the life quality and life loss of the

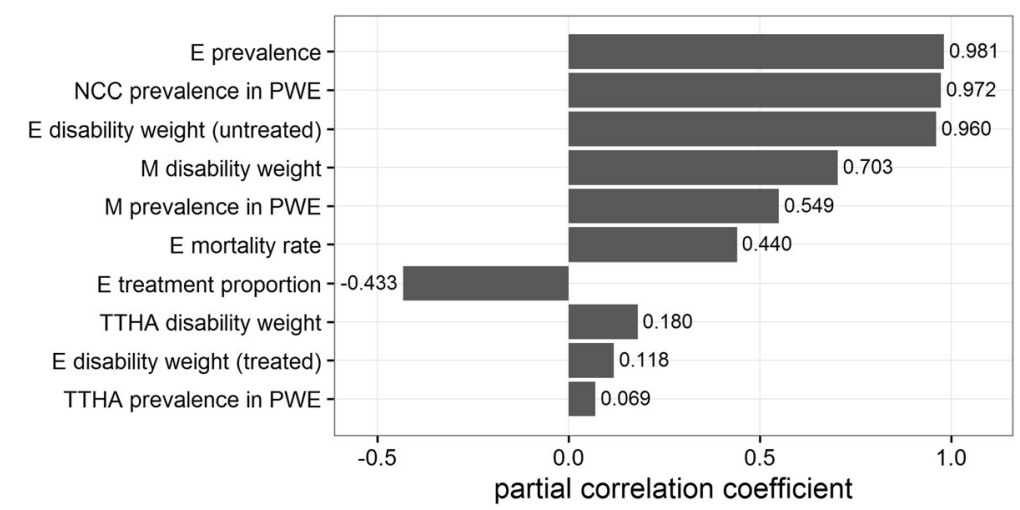

Fig. 3 Partial correlation coefficients showing which parameter influences the estimated DALYs due to NCC-associated epilepsy, migraine and tension-type headache for the year 2007 in Angónia district, Mozambique. E-epilepsy; NCC-neurocysticercosis; PWE-people with epilepsy; Mmigraine; TTHA-tension-type headache 


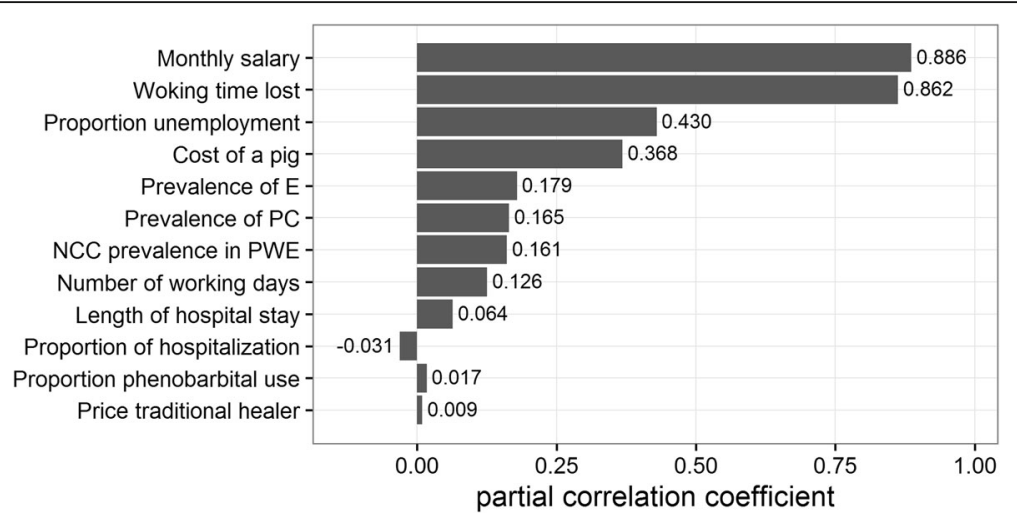

Fig. 4 Partial correlation coefficients showing which parameter influences the estimated economic burden due to NCC-associated epilepsy and porcine cysticercosis for the year 2007 in Angónia district, Mozambique. E-epilepsy; PC-porcine cysticercosis NCC-neurocysticercosis; PWE-people with epilepsy

inhabitants. However when using non-uniform age weighting and a 3\% discount rate $73 \%$ (95\% UI, 61-82) were attributed to YLD and 27\% (95\% UI, 18-39) to YLL, respectively, in contrast with results of the study in Cameroon, where the percentages of YLD and YLL were $15 \%$ and $85 \%$, respectively.

The results of the cost estimation showed that $T$. solium contributes to a high economic impact in Angónia district. Around 90,000 USD were lost due to the disease annually. Per NCC-associated epilepsy case the annual economic burden in the district amounted at 33 USD (95\% UI, 1076). Compared to other studies that assessed the economic burden of $T$. solium, these results are low. In Tanzania and Cameroon, the cost per NCC-associated epilepsy case was more than three and seven times higher, respectively. The difference can partly be explained by the large treatment gap, and partly by the low treatment costs.

The losses due to inactivity were $82 \%$ of the costs for NCC-associated epilepsy. This percentage is in line with that in Cameroon, where $89 \%$ of the total costs due to NCC-associated epilepsy were lost due to inactivity and Tanzania where around half the total costs were due to unemployment and/or inactivity of patients with NCCassociated epilepsy.

The losses due to porcine cysticercosis were estimated to be around 22,000 USD (0.07 USD per capita per infected pigs). This result is in line with estimates from Cameroon, where two studies found that 0.10 Euro per person per infected pig were lost [13, 38]. In Eastern Cape Province, South Africa the annual loss per person per infected pig was 0.60 Euro. The differences in losses might be reflected by the disease prevalence, the price reduction due to infection and pig value. The higher losses in Angónia district and in South Africa may be due to the higher prevalence of porcine cysticercosis observed in these two areas and to a different price reduction used in the estimations. In Angónia district the average value of an adult pig was 55 USD, while in Cameroon it was almost the double (100 Euro). Furthermore, in Angónia district the price reduction of a pig diagnosed with cysticercosis was $50 \%$, while in Cameroon 30\% (Gule, Personal communication) [13].

Angónia district was characterized by Pondja et al. (2010) as a rural area with very high level of illiteracy, free roaming pigs, lack of proper slaughtering facilities, frequent consumption of undercooked, uninspected pork, open latrines allowing pigs' free access, and no awareness of transmission of the diseases or ways to control it. According to FAO, the pig population in Mozambique has increased from 170,000 to 1.4 million in 20 years, an eight fold increase, which is most significant in the North [39]. With the increase of the pig population and the presence of risk factors for parasite transmission, the burden of this zoonosis will further exacerbate the life of people and pigs living in the district.

Our study has some limitations. Due to lack of information on frequency and disability weights, only the most frequent clinical symptoms of NCC (epilepsy and headache) were included in the estimates [40]. Headache is a common and non-specific symptom, and while it is a recognized association with NCC it is often not diagnosed as a symptom associated with NCC as such. In this burden assessment headache was only included as an additional symptom among the patients suffering from NCC-associated epilepsy, possibly leading to an under-estimated total burden.

The proportion of the total costs due to hospitalization was attributed to the assumption that patients injured during an epileptic seizure would be hospitalized. Furthermore in Africa the causes of epilepsy are often attributed to supernatural forces that lead to stigmatization, marginalization and exclusion of diseased people [23]. These are social aspects that are difficult to 
capture however recently the Kilifi Stigma Scale for Epilepsy, a new tool to measure perceived stigma among people with epilepsy was developed and validated [41]. This tool could assess in a study on young people with epilepsy conducted in Tanzania the impact of epilepsy on social transitioning outcomes and showed that these pupils with epilepsy were more likely to experience unfavorable educational, relationship and employment outcomes in the transition to adult life than controls [42]. This calls for models for disease burden estimates to be further improved and include sociological aspects to provide a more accurate and comprehensive estimate of the burden of disease.

In regards to porcine cysticercosis, due to the unavailability of a reliable number of the total pig population, this number had to be estimated. This will lead to inaccuracy in the derived prevalence and thus number of infected pigs and pig production losses. Furthermore, with the lack of organized/official market for pigs and associated listing, the value of a pig slaughtered/sold will remain a qualified estimate. The same regards the per cent loss in value due to cysticercosis - a reduced price may change the decision of a farmer to slaughter or sell.

It should be underlined that the epidemiological parameters used to estimate the health and economic burden in this study were collected in parallel from humans and pigs in a specific district in northern Mozambique, which is different from other studies.

From the results of this study and the comparison with the studies carried out previously on the burden of $T$. solium it is important to underline that both, the health and economic estimations depend on prevalence estimates, therefore it is essential to have accurate data in order to generate accurate burden estimates.

\section{Conclusion}

Results of this study showed that in Angónia district, Tete province, Mozambique endemic to T. solium the infection affects the livelihood of the subsistence farmers by reducing their societal and economic wellbeing. A large number of individuals suffer from NCC-associated epilepsy and headache. Healthy years of life are lost and people are left living with disabilities. Infected pork poses a serious risk to the community and hinders the economy of smallholder farmers. Cost for treatment and hospitalization of patients with NCC-associated epilepsy, and lack of productivity of suffering patients further lead to an important obstacle to socioeconomic development.

Feasible solutions framed within a country specific algorithm and stepwise approaches are needed to control the parasite in the country.

\section{Acknowledgements}

The authors are indebted to the Serviços Provinciais de Pecuária de Tete, Serviços Distritais de Agricultura de Angónia, Estação Zootécnica de
Angónia, community authorities and pig-rearing farmers for their valuable co-operation.

\section{Funding}

The work was supported by the Danish International Development Agency: CESA-project (Cross-disciplinary risk assessment of Cysticercosis in Eastern and Southern Africa) file no. 104.Dan.8.L.721 and SLIPP-project (Securing rural Livelihoods through Improved smallholder Pig Production in Mozambique and Tanzania) file no. 09-007LIFE.

\section{Availability of data and materials}

The datasets used and/or analysed during the current study are available from the corresponding author on reasonable request.

\section{Authors' contributions}

$C T, M V J, B D, N P$ designed the study; $B D, N P$ revised the models; YAA provided data on human cysticercosis; AP provided data on porcine cysticercosis; CT reviewed the literature; CT wrote the paper; CT, MVJ, BD, NP, YAA, AP, PD, SMT and PM interpreted the data, were involved in drafting the manuscript, revised and approved its final version.

Ethics approval and consent to participate Not applicable.

\section{Consent for publication}

Not applicable.

\section{Competing interests}

The authors declare that they have no competing interests.

\section{Publisher's Note}

Springer Nature remains neutral with regard to jurisdictional claims in published maps and institutional affiliations.

\section{Author details}

'Department of Veterinary and Animal Sciences, Faculty of Health and Medical Sciences, University of Copenhagen, Frederiksberg, Denmark.

2Department of Biomedical Sciences, Institute of Tropical Medicine, Antwerp, Belgium. ${ }^{3}$ Department of Public Health and Surveillance, Scientific Institute of Public Health, Brussels, Belgium. ${ }^{4}$ Faculty of Veterinary Medicine, Eduardo Mondlane University, Maputo, Mozambique. ${ }^{5}$ Department of Neurology, University of Pretoria, Pretoria, South Africa. ${ }^{6}$ Medical Faculty, Eduardo Mondlane University, Maputo, Mozambique. 'Department of Virology, Parasitology and Immunology, Faculty of Veterinary Medicine, Ghent University, Merelbeke, Belgium. ${ }^{8}$ Centre for Medical Parasitology, Department of Immunology and Microbiology, Faculty of Health and Medical Sciences, University of Copenhagen, Copenhagen, Denmark.

Received: 25 July 2017 Accepted: 1 March 2018

Published online: 13 March 2018

\section{References}

1. Braae UC, Saarnak CF, Mukaratirwa S, Devleesschauwer B, Magnussen P, Johansen MV. Taenia solium taeniosis/cysticercosis and the co-distribution with schistosomiasis in Africa. Parasit Vectors. 2015;8:323.

2. Coral-Almeida M, Gabriël S, Abatih EN, Praet N, Benitez W, Dorny P. Taenia solium human Cysticercosis: a systematic review of Sero-epidemiological data from endemic zones around the world. PLoS Negl Trop Dis. 2015;9(7): e0003919.

3. Wu HW, Ito A, Ai L, Zhou XN, Acosta LP, Lee Willingham lii A. Cysticercosis/ taeniasis endemicity in Southeast Asia: current status and control measures. Acta Trop. 2017;165:121-32.

4. Garcia HH, Gonzalez AE, Evans CAW, Gilman RH. Cysticercosis working group: Taenia solium cysticercosis. Lancet. 2003;362(9383):547-56.

5. Moyano LM, O'Neal SE, Ayvar V, Gonzalvez G, Gamboa R, Vilchez P, Rodriguez S, Reistetter J, Tsang VC, Gilman RH, et al. High prevalence of asymptomatic Neurocysticercosis in an endemic rural Community in Peru. PLoS Negl Trop Dis. 2016;10(12):e0005130.

6. Trevisan C, Mkupasi EM, Ngowi HA, Forkman B, Johansen MV. Severe seizures in pigs naturally infected with Taenia solium in Tanzania. Vet Parasitol. 2016;220:67-71. 
7. Trevisan C, Johansen MV, Mkupasi EM, Ngowi HA, Forkman B. Disease behaviours of sows naturally infected with Taenia solium in Tanzania. Vet Parasitol. 2017;235C:69-74.

8. World Health Assembly resolution WHA66.12. http://www.who.int/ neglected_diseases/WHA_66_seventh_day_resolution_adopted/en/.

9. Torgerson PR, Devleesschauwer B, Praet N, Speybroeck N, Willingham AL, Kasuga F, Rokni MB, Zhou XN, Fevre EM, Sripa B, et al. World Health Organization estimates of the global and regional disease burden of 11 foodborne parasitic diseases, 2010: a data synthesis. PLoS Med. 2015;12(12): e1001920.

10. Bhattarai R, Budke CM, Carabin H, Proano JV, Flores-Rivera J, Corona T, Ivanek R, Snowden KF, Flisser A. Estimating the non-monetary burden of Neurocysticercosis in Mexico. PLoS Negl Trop Dis. 2012;6(2):e1521.

11. Carabin H, Krecek RC, Cowan LD, Michael L, Foyaca-Sibat H, Nash T, Willingham AL. Estimation of the cost of Taenia solium cysticercosis in Eastern Cape Province, South Africa. Tropical medicine \& international health : TM \& IH. 2006;11(6):906-16.

12. Devleesschauwer B, Ale A, Torgerson P, Praet N, Maertens de Noordhout C, Pandey BD, Pun SB, Lake R, Vercruysse J, Joshi DD, et al. The burden of parasitic zoonoses in Nepal: a systematic review. PLoS Negl Trop Dis. 2014; 8(1):e2634.

13. Praet N, Speybroeck N, Manzanedo R, Berkvens D, Nforninwe DN, Zoli A, Quet F, Preux P-M, Carabin H, Geerts S. The disease burden of Taenia solium Cysticercosis in Cameroon. PLoS Negl Trop Dis. 2009;3(3):e406.

14. Trevisan C, Devleesschauwer B, Schmidt V, Winkler AS, Harrison W, Johansen MV. The societal cost of Taenia solium cysticercosis in Tanzania. Acta Trop. 2017; 165:141-54.

15. Assane YA, Trevisan C, Schutte CM, Noormahomed EV, Johansen MV, Magnussen P. Neurocysticercosis in a rural population with extensive pig production in Angonia district, Tete Province, Mozambique. Acta Trop. 2017; 165:155-60

16. Pondja A, Neves L, Mlangwa J, Afonso S, Fafetine J, Willingham AL III, Thamsborg SM, Johansen MV. Incidence of porcine cysticercosis in Angónia district, Mozambique. Preventive veterinary medicine. 2015;118(4):493-7.

17. DDAA DD d A d A. Perfil do Distrito de Angónia, Provincia de Tete. Relatório Anual De Actividades. In. Moçambique. República de Moçambique: Ministério da Administração Estatal; 2005. p. 63.

18. Feder DR. Political instability, refugees and health care crisis in Malawi. EastAfr Geogr Rev. 1998;20(1):47-57.

19. Virtanen P, Ehrenpreis D. Growth, poverty and inequality in Mozambique. In: Country studies. New York: the international poverty Centre is jointly supported by the Brazilian Institute for Applied Economic Research. United Nations Development Programme: IPEA) and the Bureau for Development Policy. p. 2007.

20. Pondja A, Neves L, Mlangwa J, Afonso S, Fafetine J, Willingham AL, Thamsborg SM, Johansen MV. Prevalence and risk factors of porcine Cysticercosis in Angonia District, Mozambique. PLoS Negl Trop Dis. 2010; 4(2):e594.

21. Del Brutto OH, Rajshekhar V, White AC, W. Tsang VC, Nash TE, Takayanagui $\mathrm{OM}$, et al. Proposed diagnostic criteria for neurocysticercosis. Neurology. 2001:57(2):177-83.

22. Mwanjali G, Kihamia C, Kakoko DVC, Lekule F, Ngowi H, Johansen MV, Thamsborg SM, Willingham AL III. Prevalence and risk factors associated with human Taenia Solium infections in Mbozi District, Mbeya region, Tanzania. PLoS Negl Trop Dis. 2013;7(3):e2102.

23. Assane YA. Human Taenia Solium Cysticercosis in the district of Angónia, Mozambique: prevalence rates and clinical aspects. PhD Thesis. Pretoria: University of Pretoria; 2012.

24. Thurman DJ, Beghi E, Begley CE, Berg AT, Buchhalter RJ, Ding D, Hesdorffer DC, Hauser AW, Kazis L, Kobau R, et al. Standards for epidemiologic studies andsurveillance of epilepsy. Epilepsia. 2011;52(Suppl 7):2-26.

25. Carpio A, Hauser WA. Epilepsy in the developing world. Current neurology and neuroscience reports. 2009;9(4):319-26.

26. Cruz ME, Cruz I, Preux PM, Schantz P, Dumas M. Headache and cysticercosis in Ecuador, South America. Headache. 1995;35(2):93-7.

27. Winkler AS, Willingham AL, Sikasunge CS, Schmutzhard E. Epilepsy and neurocysticercosis in sub-Saharan Africa. Wien Klin Wochenschr. 2009;121:3-12.

28. Disease and injury country estimates. http://www.who.int/healthinfo/ global_burden_disease/estimates_country/en/index.html.
29. Devleesschauwer B, McDonald S, Haagsma J, Praet N, Havelaar A, Speybroeck N. DALY: the DALY calculator - a GUI for stochastic DALY calculation in R. R package version. 2014:140.

30. Devleesschauwer B, Havelaar AH, Maertens de Noordhout C, Haagsma JA, Praet N, Dorny P, Duchateau L, Torgerson PR, Van Oyen H, Speybroeck N. Calculating disability-adjusted life years to quantify burden of disease. International journal of public health. 2014;59(3):565-9.

31. Salomon JA, Vos T, Hogan DR, Gagnon M, Naghavi M, Mokdad A, Begum N, Shah R, Karyana M, Kosen S, et al. Common values in assessing health outcomes from disease and injury: disability weights measurement study for the global burden of disease study 2010. Lancet. 2012;380(9859):2129-43.

32. Salomon JA, Haagsma JA, Davis A, de Noordhout CM, Polinder S, Havelaar AH, Cassini A, Devleesschauwer B, Kretzschmar M, Speybroeck N, et al. Disability weights for the global burden of disease 2013 study. Lancet Glob Health. 2015:3(11):e712-23.

33. Murray CJ, Ezzati M, Flaxman AD, Lim S, Lozano R, Michaud C, Naghavi M, Salomon JA, Shibuya K, Vos T, et al. GBD 2010: design, definitions, and metrics. Lancet. 2012;380(9859):2063-6.

34. Gule CA. Prevalence and risk factors of porcine cysticercosis associated with traditional pig production and marketing in Angonia district, Mozambique. Master dissertation. Morogoro: Sokoine University of Agriculture Morogoro; 2008

35. Core R. Team: R: a language and environment for statistical computingR foundation for statistical computing. R foundation for statistical computing: 2016

36. Singh BB, Khatkar MS, Gill JP, Dhand NK. Estimation of the health and economic burden of neurocysticercosis in India. Acta Trop. 2017;165:161-9.

37. Murray CJ. Quantifying the burden of disease: the technical basis for disability-adjusted life years. Bull World Health Organ. 1994;72(3):429-45.

38. Zoli A, Shey-Njila O, Assana E, Nguekam JP, Dorny P, Brandt J, Geerts S. Regional status, epidemiology and impact of Taenia solium cysticercosis in western and Central Africa. Acta Trop. 2003;87(1):35-42.

39. Penrith ML, Pereira CL, Da Silva MMRL, Quembo C, Nhamusso A, Banze J. African swine fever in Mozambique: review, risk factors and considerations for control. Onderstepoort J Vet Res. 2007;74(2):149-60.

40. Carabin H, Ndimubanzi PC, Budke CM, Nguyen H, Qian YJ, Cowan LD, Stoner JA, Rainwater E, Dickey M. Clinical manifestations associated with Neurocysticercosis: a systematic review. PLoS Negl Trop Dis. 2011;5(5):e1152.

41. Mbuba CA, Abubakar A, Odermatt P, Newton CR, Carteri JA. Development and validation of the Kilifi stigma scale for epilepsy in Kenya. Epilepsy \& Behaviour. 2012;24(1):81-5.

42. Goodall J, Salema S, Walker WR, Gray WK, Burtond K, Hunter E, Rogathi J, Shali E, Mohin A, Mushi D, Owens S. Stigma and functional disability in relation to marriage and employment in young people with epilepsy in rural Tanzania. Seizure. 2017:54:27-32.

43. Tanzania. http://data.worldbank.org/country/tanzania.

44. McPake B, Hongoro C, Russo G. Two-tier charging in Maputo central hospital: costs, revenues and effects on equity of access to hospital services. BMC Health Serv Res. 2011;11:143.

\section{Submit your next manuscript to BioMed Central and we will help you at every step:}

- We accept pre-submission inquiries

- Our selector tool helps you to find the most relevant journal

- We provide round the clock customer support

- Convenient online submission

- Thorough peer review

- Inclusion in PubMed and all major indexing services

- Maximum visibility for your research

Submit your manuscript at www.biomedcentral.com/submit 